\title{
(2) OPEN ACCESS \\ Immune checkpoint inhibitor-induced takotsubo syndrome and diabetic ketoacidosis: rare reactions
}

\author{
Kieran Oldfield, ${ }^{1,2}$ Rohan Jayasinghe, ${ }^{2,3,4,5}$ Selvanayagam Niranjan, 1,2,4 \\ Sameer Chadha ${ }^{6}$
}

'Department of Medicine, Gold Coast University Hospital, Southport, QLD, Australia ${ }^{2}$ School of Medicine, Griffith University, Gold Coast, QLD, Australia

${ }^{3}$ Department of Cardiology, Gold Coast University Hospital, Southport, QLD, Australia ${ }^{4}$ School of Medicine, Bond University, Gold Coast, QLD, Australia

${ }^{5}$ School of Medicine, Macquarie University, Sydney, NSW,

Australia

${ }^{6}$ Department of Internal Medicine, Maimonides Medical Center, New York, NY, USA

\section{Correspondence to}

Dr Kieran Oldfield;

kieran.oldfield@health.qld. gov.au

Accepted 31 December 2020

Check for updates

(c) BMJ Publishing Group Limited 2021. Re-use permitted under CC BY-NC. No commercial re-use. See rights and permissions. Published by BMJ.

To cite: Oldfield $\mathrm{K}$ Jayasinghe R, Niranjan S, et al. BMJ Case Rep

2021:14:e237217.

doi:10.1136/bcr-2020-

237217

\section{SUMMARY}

Immune checkpoint inhibitors (ICls) are increasingly used to treat certain malignancies due to their higher efficacy compared with conventional chemotherapy. As familiarity with these agents increases, it is becoming apparent that a significant number of patients treated with $\mathrm{ICls}$ experience adverse events. With time, more immunerelated adverse events (IRAEs) are being recognised. It is important to be vigilant for IRAEs and recognise that a patient may have multiple IRAEs affecting multiple organ systems. Common cardiovascular adverse events associated with ICls include myocarditis, arrhythmias and pericarditis. This case report identifies a patient presenting with takotsubo syndrome followed by ketoacidosis (associated with sodium-glucose transport protein 2 (SGLT2) inhibitor) in the setting of combination ipilimumab and nivolumab therapy for metastatic melanoma.

\section{BACKGROUND}

Immune checkpoint inhibitors (ICIs) are increasingly used to treat certain malignancies due to their higher efficacy compared with conventional chemotherapy. Emergence of ICI is a turning point in the field of immuno-oncology. Tumour cells escape immunosurveillance by activation of immune checkpoint pathways that inhibits antitumour immune responses. ICIs reactivate antitumour immune responses by blocking co-inhibitory signalling pathways and promote immune-mediated destruction of tumour cells.

As familiarity with these agents increases, it is becoming apparent that a significant number of patients treated with ICIs experience adverse events. Literature suggests that $75 \%-90 \%$ of patients on a cytotoxic $\mathrm{T}$ lymphocyte antigen-4 (CTLA-4) inhibitor and $30 \%-70 \%$ of patients on an antiprogrammed cell death protein-1 (PD-1)-blocking and/or anti-programmed cell death protein-1 ligand (PD-L1)-blocking monoclonal antibody experience an immune-related adverse event (IRAE). ${ }^{23}$ Combination therapy has up to a $40 \%$ higher rate of grade 3 or 4 adverse events. ${ }^{4}$ Common cardiovascular adverse events associated with ICIs include myocarditis, arrhythmias and pericarditis. There are published case reports of ICI-triggered takotsubo syndrome (TS). ${ }^{5-8}$ ICI-induced endocrinopathies are well described in the literature and these occur at a higher frequency with combination therapy. ${ }^{9}$ This case report identifies a patient presenting with TS followed by ketoacidosis (associated with SGLT2 inhibitor) in the setting of combination ipilimumab and nivolumab (Ipi/Nivo) therapy for metastatic melanoma.

\section{CASE PRESENTATION}

A 76-year-old man presented to the emergency department with central crushing chest pain and diaphoresis. This was on a background of metastatic melanoma with intracranial metastases, and a transfusion of Ipi/Nivo therapy in the preceding weeks. Two months prior to his presentation, he had had a craniotomy and debulking of his intracranial metastases. His other past comorbidities included type 2 diabetes mellitus (for which he took empagliflozin, an SGLT2 inhibitor), dyslipidaemia and hypertension. An ECG performed in the emergency department at presentation revealed 1-2 $\mathrm{mm}$ ST elevation in leads V2-V6 (figure 1). The initial management included sublingual glyceryl trinitrate, anticoagulation with enoxaparin, aspirin and fentanyl, and this resulted in the resolution of the ST segments elevation on subsequent ECG. He was taken to the Cath lab and as his ST segments had resolved the on-call interventionalist deemed it prudent to seek an oncology and neurosurgical opinion about the safety of heparin, dual antiplatelets and a staged angiogram.

\section{INVESTIGATIONS}

His initial troponin I was $938 \mathrm{ng} / \mathrm{L}$, which subsequently peaked at $2679 \mathrm{ng} / \mathrm{L}$ with the reference range being $<20 \mathrm{ng} / \mathrm{L}$. He was cleared by neurosurgery and subsequently underwent coronary angiography. This revealed non-obstructive coronary artery disease (CAD) (figure 2) and the leftventriculogram showed reduced left ventricular ejection fraction (LVEF) of about $40 \%$ with apical ballooning. Echocardiogram showed an LVEF of $50 \%$ and apical akinesis with ballooning and hyperkinetic basal and mid segments (video 1). This picture was consistent with TS. A detailed history did not reveal any recent emotional or physical stress. He made an uneventful recovery and was discharged from the hospital. On discharge, his troponin had already started to decrease, falling to $1428 \mathrm{ng} / \mathrm{L}$ indicating no ongoing insult to his myocardium.

Six days later, the patient received his second course of Ipi/Nivo. Four days after the ICI treatment, he re-presented with recurrent chest pain. His initial troponin I of $26 \mathrm{ng} / \mathrm{L}$ rose to $674 \mathrm{ng} / \mathrm{L}$ within 2 hours. Blood tests revealed diabetic ketoacidosis (DKA) with a blood glucose level of 24.6 $\mathrm{mmol} / \mathrm{L}$ (normal range 3-7.8 $\mathrm{mmol} / \mathrm{L}$ ), ketones of 


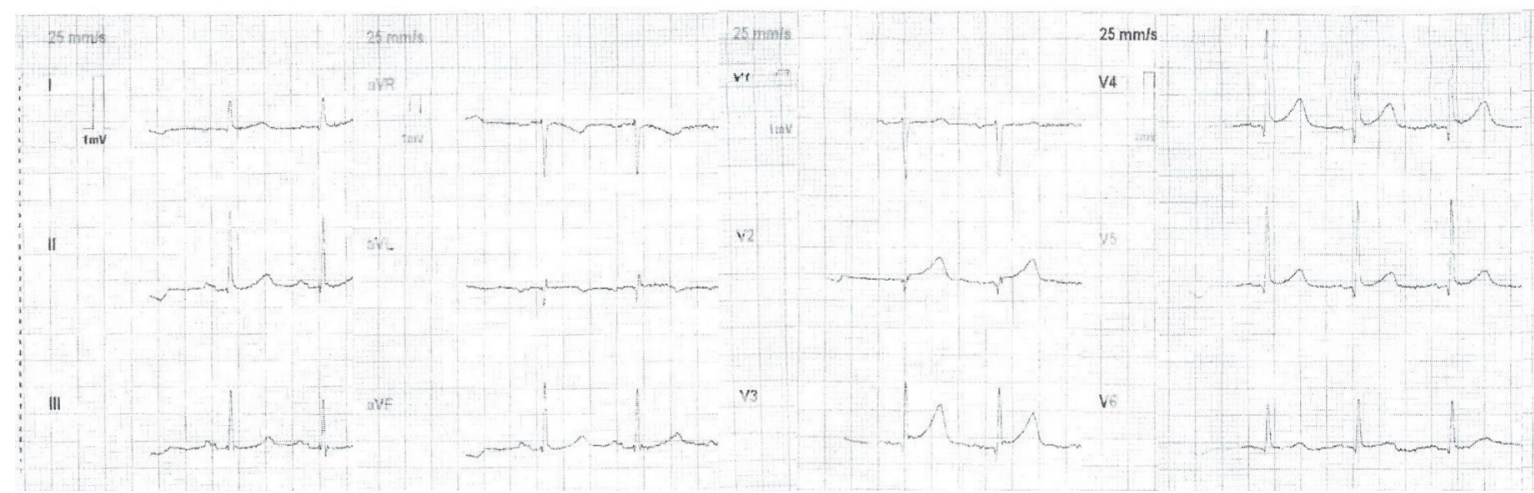

Figure 1 ECG on initial presentation.

$6.6 \mathrm{mmol} / \mathrm{L}$ (range $<1 \mathrm{mmol} / \mathrm{L}$ ) and a $\mathrm{pH}$ of 7.12 (normal range 7.32-7.43). He was managed with nitrates, antiplatelet agents and enoxaparin once again together with intravenous rehydration, but an angiogram was not performed. An echocardiogram demonstrated ongoing hypokinesis of the apical segments.

The troponin levels returned to normal soon after the symptoms got resolved. Clinical features were not suggestive of myocarditis.

\section{DIFFERENTIAL DIAGNOSIS}

To exclude the possibility of ICI-induced myocarditis, a cardiac MRI was performed. The MRI showed normal systolic function, an ejection fraction of $66 \%$ and normal left ventricular myocardial mass and ventricular wall thickness. There was mild hypokinesis of the apical segments consistent with previous history of TS. There was no myocardial gadolinium enhancement to suggest myocarditis.

In this clinical setting, it is clear that the TS and subsequent ketoacidosis were secondary to the infusion of ipilimumab and nivolumab as there was no other diagnosis or aetiology identified. The development of ketoacidosis is consistent with emplagliflozin therapy and immune-stress response associated with ICI therapy.

\section{TREATMENT}

Following our patient's first episode of TS, he was placed on aspirin, a long-acting beta-blocker (bisoprolol) and an ACE inhibitor (ramipril) for management of his TS and their cardioprotective benefits. On his initial presentation, it was not clear that there was a direct correlation between the ICI and his TS. The managing oncology team felt that due to the severity of his disease and the unclear correlation of his TS with his previous ICI infusion, there was no barrier in recieving his second ICI

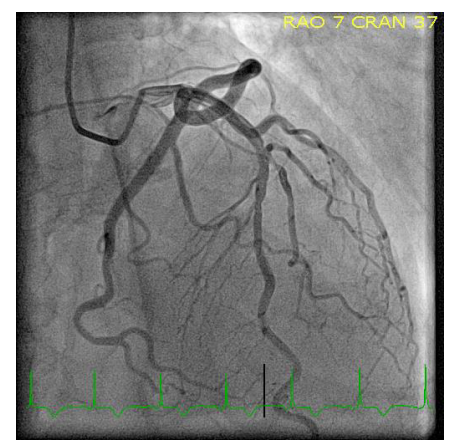

Figure 2 Angiogram on initial presentation. infusion. Following his second infusion and subsequent DKA and TS, he was determined to be for no further ICI infusions due to complications and commenced on corticosteroids as treatment for his IRAEs.

\section{OUTCOME AND FOLLOW-UP}

Our patient made a successful recovery from his TS and DKA. His cardiac MRI showed a normalised LVEF and systolic function post his second presentation. There were no further DKA or cardiac events. Despite receiving no further ICI treatments, our patient unfortunately had further IRAEs experiencing ICIinduced colitis and hepatitis, requiring months of high dose corticosteroids and mycophenolate.

\section{DISCUSSION}

Our patient had a classic presentation of TS. A literature review of TS found that an emotional or physical stress is present as the trigger in $39 \%$ and $35 \%$ of patients, respectively. ${ }^{10}$ Having excluded acute coronary syndrome, myocarditis and physical and emotional stress in conjunction with the observation that two sequential episodes of TS followed the same dual ICI therapy confirms the observation that TS was secondary to ipilimumab and nivolumab treatment.

Historically TS has been considered a benign condition with a favourable prognosis. ${ }^{11}$ Recent data shows that indeed TS secondary to emotional triggers has a favourable outcome compared with CAD, however overall TS has comparable

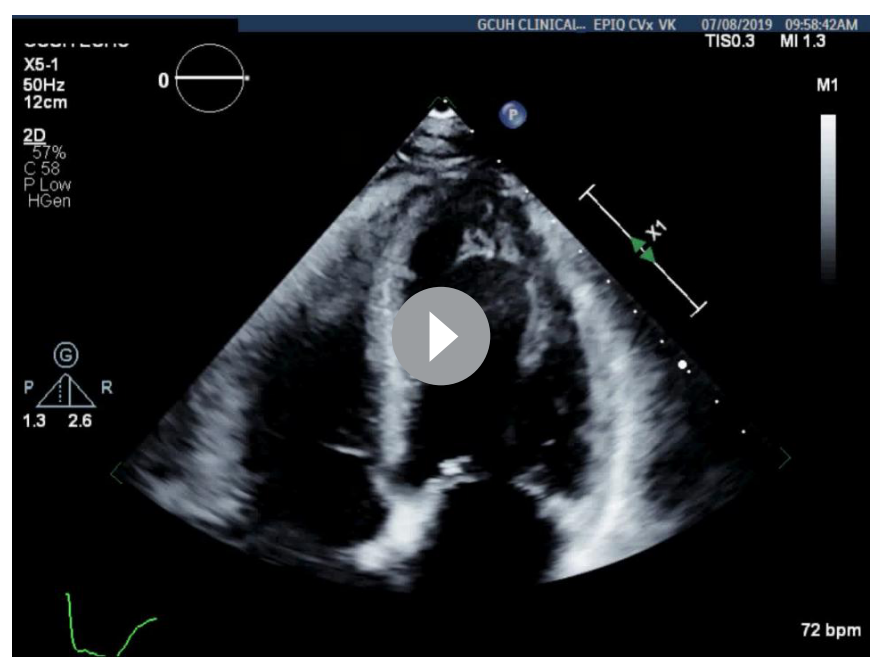

Video 1 Echocardiogram on initial presentation. 
mortality outcomes to age-controlled patients with CAD. TS secondary to a physical trigger has a worse 5 -year mortality than $\mathrm{CAD}$, likely due to the underlying comorbid state of the patient population. ${ }^{12} 13$

There have been reports in the literature of TS secondary to ICIs and a proportionality study found that there was an increased OR of TS when compared with positive and negative controls. ${ }^{6-8}$ The precise pathophysiology of TS in the setting of ICIs is unclear and imaging studies have not consistently shown myocardial oedema. ${ }^{78}$ The proposed mechanism of injury in ICI-induced myocarditis is lymphocyte (CD4+ and CD8+ $\mathrm{T}$ cells) and macrophage infiltration of the myocardium. ${ }^{14}$ There has also been a case report of lymphocytic myocarditis mimicking TS, which may imply that some of these cases are atypical myocarditis. ${ }^{15}$ The lack of gadolidium enhancement and myocardial oedema in our patient is consistent with the previously published case reports, suggesting that ICIs can cause TS without myocarditis.

Our literature review revealed no case reports of ICI-induced euglycaemic or hyperglycaemic DKA in the setting of concurrent SGLT2 inhibitor. However, considering our patient's hyperglycaemia and his significant ketoacidotic state, it is possible that SGLT2 inhibitor therapy contributed to the metabolic disturbance in the setting of ICI, and it remains unknown whether this is an atypical manifestation of euglycaemic DKA. ICI-induced diabetes (type 1 ) has been reported ${ }^{16-18}$ with an estimated incidence of $1 \%{ }^{18}$ and approximately $76 \%$ of new cases present with DKA. ${ }^{16}$ Our patient had established type 2 diabetes.

An antibody screen showed antibodies to glutamic acid decarboxylase (anti-GAD) antibodies of 1012 (upper limit of normal $<5)$. Anti-GAD antibodies have been reported as the most common antibody associated with ICI-induced type 1 diabetes. ${ }^{16}$ It is not possible to determine whether the development of ketoacidosis was related to the presence of TS or a manifestation of ICI immune-mediated toxicity, or alternately unrelated to both as ketoacidosis associated with SGLT2 therapy, although not too common, is well recognised.

In conclusion, ICIs are showing exceptional promise as the new frontier in treating malignancies. It is important to be vigilant for IRAEs and recognise that a patient may have multiple IRAEs affecting multiple organ systems. Over time, new case reports and data are bringing to light the many manifestations of IRAEs. Knowledge and science related to ICI therapy are improving with enhanced efficacy as well as safety. More

\section{Learning points}

- Immune checkpoint inhibitor (ICI)-induced takotsubo syndrome (TS) is an increasingly recognised clinical phenomenon.

- Patients may have more than one immune-related adverse event (IRAE) when being treated with ICls and they may affect multiple organ systems. They may occur after treatment with these agents has been ceased.

- ICl-induced myocarditis is still the most common cardiac IRAE, and it can mimic TS echographically. research is required to identify best means of prevention and management of such adverse effects (IRAEs) as the use of these agents become more prevalent.

Contributors $\mathrm{KO}$ wrote most of the article and performed the majority of the literature review. All the drafts that were made were written by $\mathrm{KO}$ and then sent to the other authors for review, critical analysis and editing. RJ was responsible for planning the case report. He aided in the editing process and critical revision as well as helped to write sections. SN was responsible for revising the drafts, editing, critical revision and design of the case report. SC was responsible for revising drafts, editing drafts and critical revision. Each author had substantial contributions to the review process, literature review and design of the case report.

Funding The authors have not declared a specific grant for this research from any funding agency in the public, commercial or not-for-profit sectors.

Competing interests None declared.

\section{Patient consent for publication Obtained.}

Provenance and peer review Not commissioned; externally peer reviewed.

Open access This is an open access article distributed in accordance with the Creative Commons Attribution Non Commercial (CC BY-NC 4.0) license, which permits others to distribute, remix, adapt, build upon this work non-commercially, and license their derivative works on different terms, provided the original work is properly cited and the use is non-commercial. See: http://creativecommons.org/ licenses/by-nc/4.0/.

\section{REFERENCES}

1 Darvin P, Toor SM, Sasidharan Nair V, et al. Immune checkpoint inhibitors: recent progress and potential biomarkers. Exp Mol Med 2018;50:1-11.

2 Michot JM, Bigenwald C, Champiat S, et al. Immune-related adverse events with immune checkpoint blockade: a comprehensive review. Eur J Cancer 2016:54:139-48

3 Tajiri K, leda M. Cardiac complications in immune checkpoint inhibition therapy. Front Cardiovasc Med 2019:6:3

4 Yang S, Asnani A. Cardiotoxicities associated with immune checkpoint inhibitors. Curr Probl Cancer 2018:42:422-32.

5 Ball S, Ghosh RK, Wongsaengsak S, et al. Cardiovascular Toxicities of Immune Checkpoint Inhibitors: JACC Review Topic of the Week. J Am Coll Cardiol 2019;74:1714-27.

6 Ederhy S, Dolladille C, Thuny F, et al. Takotsubo syndrome in patients with cancer treated with immune checkpoint inhibitors: a new adverse cardiac complication. Eur J Heart Fail 2019:21:945-7

7 Ederhy S, Cautela J, Ancedy Y, et al. Takotsubo-like syndrome in cancerpatients treated with immune checkpoint inhibitors. JACC Cardiovasc Imaging 2018;11:1187-90.

8 Geisler BP, Raad RA, Esaian D, et al. Apical ballooning and cardiomyopathy in a melanoma patient treated with ipilimumab: a case of takotsubo-like syndrome. $J$ Immunother Cancer 2015:3:4.

9 Zhai Y, Ye X, Hu F, et al. Endocrine toxicity of immune checkpoint inhibitors: a realworld study leveraging US food and drug administration adverse events reporting system. J Immunother Cancer 2019;7:286.

10 Pelliccia F, Parodi G, Greco C, et al. Comorbidities frequency in takotsubo syndrome: an international collaborative systematic review including 1109 patients. Am J Med 2015;128:654.e11-654.e19.

11 Gianni M, Dentali F, Grandi AM, et al. Apical ballooning syndrome or takotsubo cardiomyopathy: a systematic review. Eur Heart J 2006;27:1523-9.

12 Ghadri JR, Kato K, Cammann VL, et al. Long-term prognosis of patients with takotsubo syndrome. J Am Coll Cardiol 2018;72:874-82.

13 Tornvall $P$, Collste 0 , Ehrenborg $E$, et al. A case-control study of risk markers and mortality in takotsubo stress cardiomyopathy. J Am Coll Cardiol 2016;67:1931-6.

14 Varricchi G, Galdiero MR, Marone G, et al. Cardiotoxicity of immune checkpoint inhibitors. ESMO Open 2017;2:e000247.

15 Caforio ALP, Tona F, Vinci A, et al. Acute biopsy-proven lymphocytic myocarditis mimicking takotsubo cardiomyopathy. Eur J Heart Fail 2009;11:428-31.

16 Akturk HK, Kahramangil D, Sarwal A, et al. Immune checkpoint inhibitor-induced type 1 diabetes: a systematic review and meta-analysis. Diabet Med 2019;36:1075-81.

17 de Filette JMK, Pen JJ, Decoster L, et al. Immune checkpoint inhibitors and type 1 diabetes mellitus: a case report and systematic review. Eur J Endocrinol 2019;181:363-74.

18 Stamatouli AM, Quandt Z, Perdigoto AL, et al. Collateral damage: insulin-dependent diabetes induced with checkpoint inhibitors. Diabetes 2018;67:1471-80. 
Copyright 2021 BMJ Publishing Group. All rights reserved. For permission to reuse any of this content visit https://www.bmj.com/company/products-services/rights-and-licensing/permissions/

BMJ Case Report Fellows may re-use this article for personal use and teaching without any further permission.

Become a Fellow of BMJ Case Reports today and you can:

- Submit as many cases as you like

- Enjoy fast sympathetic peer review and rapid publication of accepted articles

Access all the published articles

- Re-use any of the published material for personal use and teaching without further permission

Customer Service

If you have any further queries about your subscription, please contact our customer services team on +44 (0) 2071111105 or via email at support@bmj.com.

Visit casereports.bmj.com for more articles like this and to become a Fellow 